\title{
Influence of erdosteine, a mucolytic agent, on amoxycillin penetration into sputum in patients with an infective exacerbation of chronic bronchitis
}

\author{
GIOVANNI RICEVUTI, ANTONINO MAZZONE, ELVIRA UCCELLI, \\ GABRIELLA GAZZANI, GIANCARLO B FREGNAN
}

From the Section of Medical Pathology I, Department of Internal Medicine and Therapeutics, University of Pavia; the Department of Pharmaceutical Chemistry, University of Pavia; and the Research Center

Laboratories, Edmond Pharma SRL, Milan, Italy

\begin{abstract}
Twenty four patients with acute infective exacerbations of chronic bronchitis received amoxycillin alone or in combination with erdosteine (a mucolytic agent) for a week in a double blind, placebo controlled study. Clinical assessment scores, body temperature, serum and sputum amoxycillin concentrations, and sputum culture results were recorded in each group. Erdosteine significantly increased antibiotic concentrations in sputum but not in serum. The combined treatment also caused a more rapid decrease in sputum viscosity and in body temperature and faster sterilisation of the sputum. These results show that erdosteine increases amoxycillin concentration in sputum in patients with acute exacerbations of chronic bronchitis. This effect may be due to a reduction in the viscosity of the bronchial secretions produced by erdosteine.
\end{abstract}

\section{Introduction}

Although the exact role of bacterial infections in acute exacerbations of chronic bronchitis is not clear, antibiotic treatment is widely used. In some patients, however, the high viscosity of the bronchial secretions may impair local antibiotic penetration. Previous studies $^{1-5}$ have shown that administration of a mucolytic agent with an antibiotic can increase sputum concentrations of the latter.

A new thiol derivative (erdosteine) with two blocked $\mathrm{S}-\mathrm{H}$ radicals has recently been synthesised by Gobetti et al. ${ }^{6}$ The drug has mucokinetic properties and is effective in reducing the viscosity of bronchial secretions. Pharmacodynamic studies in animals and man indicate that the drug is well tolerated and devoid of side effects.

The purpose of this study was to evaluate the penetration of amoxycillin into the sputum after single and multiple oral doses of the antibiotic given either alone or in combination with erdosteine. The concentrations achieved were compared with its in vitro antibacterial activity and related to the subsequent disappearance of clinical symptoms.

\footnotetext{
Address for reprint requests: Professor G B Fregnan, Edmond Pharma, via Gradisca 8, 20151 Milan, Italy.
}

\section{Methods}

\section{PATIENTS}

Twenty four patients ( 10 male and 14 female, aged 4571 years) with chronic bronchitis were studied during an acute, severe infective exacerbation. Thirteen patients also had asthma. All patients, formerly heavy smokers ( $>20$ cigarettes/day), smoked fewer than 15 cigarettes a day at the time of the study. Pathogenic bacteria sensitive to amoxycillin were isolated from their sputum. None of the patients had received antibiotics, mucolytic drugs, or corticosteroids during the previous two weeks. The patients were allowed to inhale $\beta_{2}$ adrenergic bronchodilators during the trial (three asthmatic patients in each group). No patients had liver or kidney disease, and all gave written consent.

\section{STUDY DESIGN}

The study was double blind. A doctor (not responsible for disease follow up or data analysis) was assigned the task of dividing the patients into two groups matched for sex, sputum pathogen, and history of concomitant asthma. Lung function (not determined) and degree of reversibility were not factors in the selection of these groups. The first group received amoxycillin $500 \mathrm{mg}$ thrice daily and erdosteine $300 \mathrm{mg}$ thrice daily and the second amoxycillin $500 \mathrm{mg}$ and placebo, both thrice 
daily. The drugs were administered orally for seven days. The staff who scored symptoms and undertook laboratory investigations were unaware of the difference in the treatments.

A positive clinical response was considered to have occurred on the first day on which the patient became afebrile or the sputum was converted from mucopurulent to mucoid.

\section{CLINICAL ASSESSMENT}

Cough and dyspnoea intensity, sputum appearance (viscosity and purulence), and body temperature were determined daily and, except for the last, graded on a scale from 0 to 3 according to the following scheme:

\begin{tabular}{lllll} 
Score & Cough & Dyspnoea & Sputum \\
\cline { 3 - 5 } & Viscosity & Purulence \\
\hline 1 & $\begin{array}{l}\text { Absent } \\
\text { Minimal }\end{array}$ & $\begin{array}{l}\text { Absent } \\
\text { With moderate } \\
\text { exertion } \\
\text { (climbing stairs) }\end{array}$ & $\begin{array}{l}\text { Normal } \\
\text { Slight }\end{array}$ & $\begin{array}{l}\text { Salivous } \\
\text { Mucoid }\end{array}$ \\
2 & Moderate & $\begin{array}{l}\text { With minimal } \\
\text { exertion (walking } \\
\text { 200-300 m) }\end{array}$ & Moderate & Mucopurulent \\
3 & Severe & At rest & Marked & Purulent
\end{tabular}

\section{SPECIMEN COLLECTION}

Samples of sputum and serum were collected 0,3 , and 6 hours after the first and the 19th dose of amoxycillin (performed on the seventh morning). Sputum was collected in plastic containers for $\mathbf{3 0}$ minutes before the appointed collection times and was immediately classified by its appearance on naked eye examination.

\section{ANTIBIOTIC ASSAY}

Amoxycillin concentrations in sputum and serum samples were measured microbiologically by the plate agar diffusion method, with a punch hole technique and Sarcina lutea ATCC 9341 as test organism. Before assay the sputum was homogenised in equal quantities of sterile distilled water with glass beads. The samples were further diluted when necessary. Twofold dilutions of amoxycillin in sterile distilled water at final concentrations of $1 \cdot 0,0 \cdot 5,0 \cdot 25,0 \cdot 12,0 \cdot 06$, and $0.03 \mu \mathrm{g} /$ $\mathrm{ml}$ were prepared immediately before use. A full set of dilutions was included in each batch of assay for the preparation of the standard curves from which the drug concentrations in the specimens were calculated. The specimens and standard dilutions were set up in duplicate. The plates were incubated for 24 hours and the mean diameters of the inhibition zones were used for determining the drug concentrations. All assays were performed on the collection day. In a separate experiment the antibacterial activity of erdosteine alone or combined with amoxycillin was tested on Sarcina lutea and other specimens freshly isolated from sputum (that is, Streptococcus pneumoniae Haemophilus influenzae, and several staphylococci) by the agar plate diffusion method. Erdosteine was also added in vitro to some sputum from patients receivin amoxycillin plus placebo and tested against the same bacteria. Some samples were also analysed by high pressure liquid chromatography according to the method described by Carlqvist and Westerlund. ' The biological fluids, deproteinised with dichloroethane and perchloric acid, were then centrifuged and the aqueous phases injected into a high pressure liquid chromatography apparatus equipped with precolumn and a reverse phase column. The mobile phase consisted of phosphate buffer (pH 8)-methanoi $(92: 8 \mathrm{v} / \mathrm{v})$ at a flow rate of $1 \mathrm{ml} / \mathrm{min}$. The postcolumg derivatisation was performed with an aqueous solution of imidazole-mercuric chloride-Brij 35 (33\% $0 \cdot 11 \%, 0 \cdot 12 \%)$, pH $7 \cdot 2$. Absorbance was measured $310 \mathrm{~nm}$. The sensitivity of the method was $0 \cdot 1 \mu \mathrm{g} / \mathrm{n}$ f biological fluids. A fresh overnight culture of Sarcin $\vec{\Phi}$ lutea was prepared and washed from an agar slope with sterile distilled water to give a suspension with $50 \%$ transmission at $650 \mathrm{~nm}$ on a visible spectro photometer. The suspension was shaken for one hour to produce homogeneity and used as $1 \%$ inoculum Assay plates were prepared with a layer of seeded agair BBL 10937 at $\mathrm{pH} 7 \cdot 0$. The assay method then followed the procedure described by Campbell. ${ }^{8}$ The lower limis of antibiotic detectability in the biological specimens was $0.03 \mu \mathrm{g} / \mathrm{ml}$ and the variability of estimation w⿳⺈⿴囗十大 less than $5 \%$.

\section{SPUTUM CULTURE}

Sputum was collected for bacterial pathogen idef tification one to three days before treatment and on the second, fourth, sixth, seventh, and eight day of treatment just before the morning dose. Sputum wass prepared as above, and cultures were set up on heateg or unheated blood agar.

Properly identified strains were recultured on ag BBL 10937 plates and their sensitivity to amoxycillï tested by disc agar diffusion bioassay. The minimuă inhibitory concentration of amoxycillin was detero mined on each strain isolated before the patients began antibiotic treatment.

STATISTICAL ANALYSIS

The data were evaluated by analysis of variance $\mathbb{\otimes}_{f}$ the Mann-Whitney U test and a statistical difference between the two treatment groups was taken as $p$ 0.05 .

\section{Results}

CLINICAL SYMPTOMS

In both groups cough, dyspnoea, sputum viscosity a 
Table 1 Change in clinical symptoms over the seven days of treatment

\begin{tabular}{|c|c|c|c|c|c|c|}
\hline \multirow[b]{2}{*}{ Treatment } & \multirow{2}{*}{$\begin{array}{l}\text { Period } \\
\text { (days) }\end{array}$} & \multicolumn{4}{|c|}{ Mean (SEM) score† } & \multirow{2}{*}{$\begin{array}{l}\text { Mean (SEM) } \\
B T\left({ }^{\circ} C\right)\end{array}$} \\
\hline & & Cough & Dyspnoea & $S V$ & $S P$ & \\
\hline $\begin{array}{l}\text { Amoxycillin plus } \\
\text { erdosteine }\end{array}$ & $\begin{array}{l}0 \\
1 \\
2 \\
3 \\
4 \\
5 \\
5 \\
6 \\
7\end{array}$ & $\begin{array}{ll}2.4 & (0.19) \\
2.5 & (0.15) \\
2.3 & (0.14) \\
1.8 & (0.21) \\
1.5(0.19) \\
1.3(0.14) \\
0.92(0.15) \\
0.67(0.19)\end{array}$ & $\begin{array}{ll}2.6 & (0.15) \\
2.4 & (0.22) \\
1.9 & (0.19) \\
1.8 & (0.17) \\
1.5(0.19) \\
1.3(0.13) \\
1.0(0.17) \\
0.58(0.19)\end{array}$ & $\begin{array}{ll}3.0 & (0.0) \\
2.9 & (0.08) \\
2.3 & (0.17) \\
1.7 & (0.14)^{*} \\
1.3(0.14)^{*} \\
1.1(0.08)^{*} \\
0.66(0.14)^{*} \\
0.41(0.14)\end{array}$ & $\begin{array}{ll}2.8 & (0.13) \\
2.8 & (0.13) \\
2.3 & (0.21) \\
2.0 & (0.21) \\
1.8 & (0.17) \\
1.3 & (0 \cdot 14) \\
0.91(0.14) \\
0.58(0.14)\end{array}$ & $\begin{array}{l}39.0(0 \cdot 12) \\
39.0(0 \cdot 10) \\
38.7(0.08)^{*} \\
38.3(0.08)^{*} \\
37.6(0 \cdot 18)^{*} \\
36.9(0.05)^{*} \\
36.8(0.03)^{*} \\
36.8(0.04)\end{array}$ \\
\hline $\begin{array}{l}\text { Amoxycillin plus } \\
\text { placebo }\end{array}$ & $\begin{array}{l}0 \\
1 \\
2 \\
3 \\
4 \\
5 \\
6 \\
7\end{array}$ & $\begin{array}{ll}2.5 & (0.15) \\
2.6 & (0.15) \\
2.3 & (0.14) \\
2.2 & (0.17) \\
2.0 & (0.17) \\
1.8 & (0.13) \\
1.4 & (0.15) \\
1.1 & (0.19)\end{array}$ & $\begin{array}{ll}2.5 & (0.15) \\
2.4 & (0 \cdot 19) \\
2.1 & (0.22) \\
1.9 & (0 \cdot 19) \\
1.8 & (0 \cdot 17) \\
1.5 & (0 \cdot 15) \\
1.3 & (0 \cdot 13) \\
0.91(0.19)\end{array}$ & $\begin{array}{ll}2.9 & (0.08) \\
2.9 & (0.08) \\
2.8 & (0.13) \\
2.7 & (0.14) \\
2.6 & (0.14) \\
1.8 & (0.17) \\
1.4 & (0.14) \\
0.91(0.14)\end{array}$ & $\begin{array}{ll}2.7 & (0 \cdot 14) \\
2.7 & (0 \cdot 14) \\
2.5 & (0 \cdot 15) \\
2.3 & (0 \cdot 14) \\
2.1 & (0 \cdot 14) \\
1.4 & (0 \cdot 14) \\
1.2 & (0 \cdot 11) \\
0.83(0.11)\end{array}$ & $\begin{array}{l}39.3(0.14) \\
39.2(0.13) \\
39.0(0.07) \\
38.7(0.09) \\
38.0(0.07) \\
37.1(0 \cdot 10) \\
37.0(0.06) \\
36.9(0.04)\end{array}$ \\
\hline
\end{tabular}

* $p=0.05$ for amoxycillin plus erdosteine $v$ amoxycillin plus placebo.

†Scale 0-3 (see under "Methods"). SV, sputum viscosity; SP, sputum purulence; BT, body temperature.

purulence, and temperature decreased progressively significantly faster rate in the patients receiving soon after the start of amoxycillin treatment (table 1). amoxycillin and erdosteine than in those receiving Sputum viscosity and temperature decreased at a amoxycillin alone.

Table 2 Pathogen isolated from patients' sputum samples before and during treatment with amoxycillin alone or in combination with erdosteine and relative minimal inhibitory concentrations $(\mu \mathrm{g} / \mathrm{ml} /)$ for amoxycillin in vitro (in parentheses)

\begin{tabular}{|c|c|c|c|c|c|c|c|}
\hline \multirow{2}{*}{$\begin{array}{l}\text { Patient } \\
\text { No }\end{array}$} & \multirow[b]{2}{*}{ Sex } & \multicolumn{6}{|c|}{ Pathogens isolated during the treatment period: days of culture } \\
\hline & & 0 & 2 day & 4 day & 6 day & 7 day & 8 day \\
\hline $\begin{array}{l}1 \\
2 \\
3^{* *} \\
4 \\
5^{* *} \ddagger \\
6^{* *} \\
7 \\
8^{* *} \dagger \ddagger \\
9 \\
10^{* *} \\
11^{* *} \dagger \ddagger \\
12^{* *}\end{array}$ & $\begin{array}{l}\mathbf{M} \\
\mathbf{M} \\
\mathbf{M} \\
\mathbf{M} \\
\mathbf{M} \\
\mathbf{F} \\
\mathbf{F} \\
\mathbf{F} \\
\mathbf{F} \\
\mathbf{F} \\
\mathbf{F} \\
\mathbf{F}\end{array}$ & $\begin{array}{l}S p(0.06) \\
S p(0.06) \\
H i(0.12) \\
H i(0.5) \\
H i(0.12) \\
S p(0.25) \\
S p(0.06) \\
H i(0.5) \\
S a(0 \cdot 12) \\
S p(0.06) \\
S p(0.06) \\
H i(0.25)\end{array}$ & $\begin{array}{c}\text { oxycillin } \\
S p \\
S p \\
H i \\
H i \\
H i \\
S p \\
S p \\
H i \\
S a \\
S p \\
S p \\
H i\end{array}$ & $\begin{array}{l}\text { teine } \\
\overline{\bar{H}} \\
\mathrm{Hi} \\
\overline{S p} \\
\overline{\mathrm{Hi}} \\
\overline{-} \\
\overline{-} \\
-\end{array}$ & $\begin{array}{l}- \\
= \\
= \\
= \\
= \\
= \\
-\end{array}$ & $\begin{array}{l}- \\
- \\
- \\
= \\
= \\
= \\
=\end{array}$ & $\begin{array}{l}- \\
= \\
= \\
= \\
= \\
= \\
=\end{array}$ \\
\hline $\begin{array}{l}13^{* *} \\
14 \\
15 \\
16 \\
17^{* *}+\ddagger \\
18 \\
19 \\
20^{* *} \\
21 \\
22^{* * \ddagger} \\
23^{* *} \\
24^{* *} \ddagger\end{array}$ & $\begin{array}{l}\mathbf{M} \\
\mathbf{M} \\
\mathbf{M} \\
\mathbf{M} \\
\mathbf{M} \\
\mathbf{F} \\
\mathbf{F} \\
\mathbf{F} \\
\mathbf{F} \\
\mathbf{F} \\
\mathbf{F} \\
\mathbf{F}\end{array}$ & $\begin{array}{l}S p(0.06) \\
H i(0 \cdot 12) \\
H i(0.18) \\
S p(0.03) \\
H i(0.5) \\
H i(0.25) \\
S p(0.06) \\
S p(0.12) \\
S p(0.06) \\
H i(0.25) \\
S a(0.12) \\
S p(0.06)\end{array}$ & $\begin{array}{c}\text { moxycill } \\
S p \\
H i \\
H i \\
S p \\
H i \\
H i \\
S p \\
S p \\
S p \\
H i \\
S a \\
S p\end{array}$ & $\begin{array}{c}e b o \\
S p \\
H i \\
H i \\
\overline{H i} \\
H i \\
\overline{S p} \\
\overline{-} \\
\overline{S a} \\
S p\end{array}$ & $\begin{array}{l}\overline{H i} \\
\overline{-} \\
\overline{H i} \\
\overline{-} \\
\overline{-} \\
\overline{H i} \\
\overline{\mathrm{Sa}} \\
-\end{array}$ & $\begin{array}{l}\overline{H i} \\
\overline{-} \\
\overline{H i} \\
\overline{-} \\
\overline{-} \\
\overline{H i} \\
\overline{S a} \\
-\end{array}$ & $\begin{array}{l}- \\
- \\
- \\
- \\
- \\
\overline{-} \\
\bar{H} i^{*} \\
-\end{array}$ \\
\hline
\end{tabular}

$S p$, Streptococcus pneumoniae; $H i$, Haemophilus influenzae; $\mathrm{Sa}$, Staphylococcus aureus (not $\beta$ lactamase producing). ** Patients who also had asthme 10 th day.

†Atopic patients.

$\ddagger$ Two or three doses $(400 \mathrm{mg}$ each) of fenoterol were inhaled the preceding week or during the trial. 


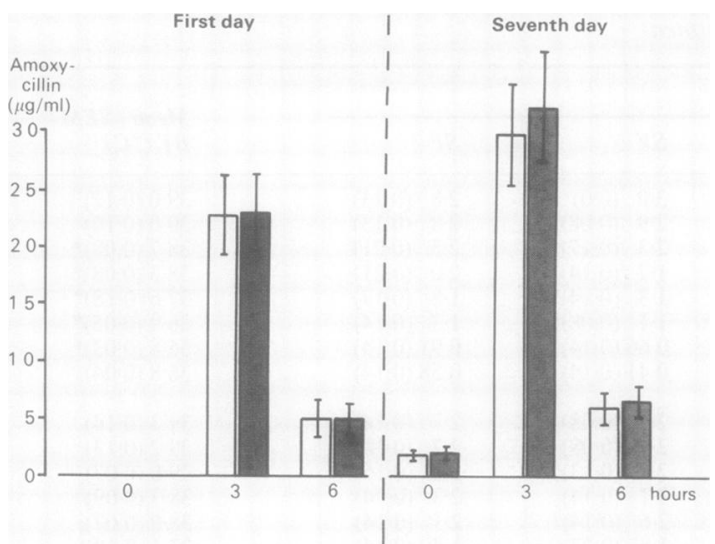

Fig 1 Serum amoxycillin concentrations after the morning dose and on day 1 and day 7 of treatment (white columns indicate amoxycillin plus erdosteine and black columns amoxycillin plus placebo).

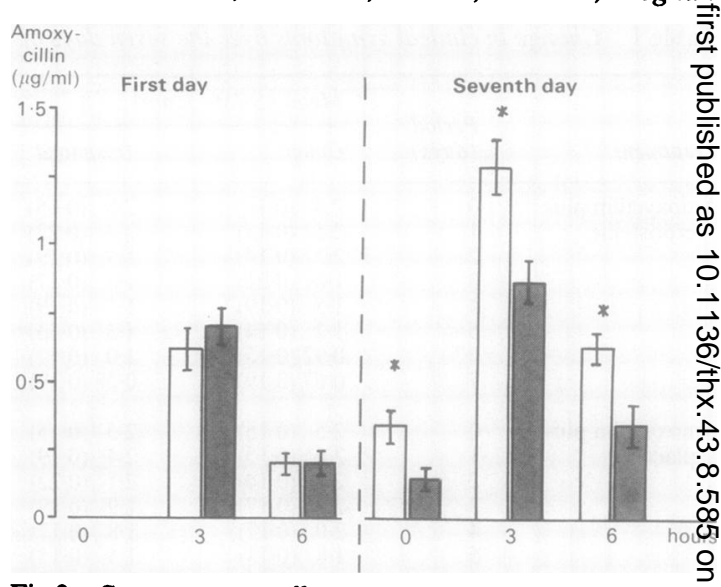

Fig 2 Sputum amoxycillin concentrations after the morningdose and on day 1 and day 7 of treatment. ${ }^{*} p=0.05$ for amoxycillin plus erdosteine (white columns) $v$ amoxycillin plus placebo (black columns).

Table 3 Amoxycillin concentrations in sputum after the morning dose on day 1 and day 7 of treatment*

\begin{tabular}{|c|c|c|c|c|c|c|}
\hline \multirow{3}{*}{$\begin{array}{l}\text { Patient } \\
\text { No }\end{array}$} & \multicolumn{6}{|c|}{ Amoxycillin concentration $(\mu \mathrm{g} / \mathrm{ml})$ on } \\
\hline & \multicolumn{3}{|c|}{ first day after (h): } & \multicolumn{3}{|c|}{ seventh day after $(h)$ : } \\
\hline & 0 & 3 & 6 & 0 & 3 & 6 \\
\hline $\begin{array}{r}1 \\
2 \\
3 \\
4 \\
5 \\
6 \\
7 \\
8 \\
9 \\
10 \\
11 \\
12\end{array}$ & $\begin{array}{l}0 \\
0 \\
0 \\
0 \\
0 \\
0 \\
0 \\
0 \\
0 \\
0 \\
0 \\
0\end{array}$ & $\begin{array}{l}0.7 \\
0.6 \\
1.2(1.1) \\
0.4 \\
0.8(0.9) \\
0.2 \\
0.5(0.6) \\
0.7 \\
0.6(0.6) \\
0.4 \\
0.5 \\
0.8\end{array}$ & \begin{tabular}{ll}
\multicolumn{2}{l}{ Amoxycilli } \\
0.2 & \\
0.3 & \\
0.5 & $(0.5)$ \\
0.07 & \\
$0 \cdot 1$ & \\
$0 \cdot 1$ & \\
$0 \cdot 2$ & \\
0.08 & $(0 \cdot 3)$ \\
0.09 & \\
0.2 & \\
0.4 & \\
0.2 &
\end{tabular} & $\begin{array}{l}0.3 \\
0.4 \\
0.3 \\
0.1 \\
0.5 \\
0.1 \\
0.6 \\
0.1 \\
0.2 \\
0.7 \\
0.4 \\
0.5\end{array}$ & $\begin{array}{l}1.6 \\
1.1 \\
1.2(1.3) \\
1.3 \\
1.5(1.3) \\
0.9 \\
2.1(2.2) \\
1.0 \\
0.8(0.8) \\
1.4 \\
1.0 \\
1.1\end{array}$ & $\begin{array}{l}0.5 \\
0.7 \\
0.8(0.9 \\
0.5 \\
0.3 \\
0.6 \\
0.4(0.4) \\
0.7 \\
0.4(0.5) \\
0.9 \\
0.8 \\
0.9\end{array}$ \\
\hline $\begin{array}{l}\text { Mean } \\
\text { SEM }\end{array}$ & 0 & $\begin{array}{l}0.62 \\
0.074\end{array}$ & $\begin{array}{l}0.20 \\
0.039\end{array}$ & $\begin{array}{l}0.34 \\
0.062 \dagger\end{array}$ & $\begin{array}{l}1 \cdot 3 \\
0 \cdot 10 \dagger\end{array}$ & $\begin{array}{l}0.63 \\
0.059+\end{array}$ \\
\hline $\begin{array}{l}13 \\
14 \\
15 \\
16 \\
17 \\
18 \\
19 \\
20 \\
21 \\
22 \\
23 \\
24\end{array}$ & $\begin{array}{l}0 \\
0 \\
0 \\
0 \\
0 \\
0 \\
0 \\
0 \\
0 \\
0 \\
0 \\
0\end{array}$ & $\begin{array}{l}0.8(0.7) \\
0.3 \\
0.8 \\
0.9(1.0) \\
0.7(0.7) \\
0.5 \\
0.6 \\
0.8(0.8) \\
0.4 \\
1.1 \\
0.9 \\
0.7\end{array}$ & 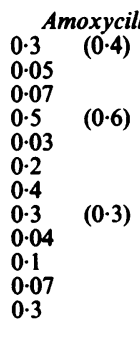 & $\begin{array}{l}0.1 \\
0.1 \\
0.1 \\
0.4 \\
0.03 \\
0.08 \\
0.08 \\
0.2 \\
0.2 \\
0.05 \\
0.3 \\
0.1\end{array}$ & $\begin{array}{l}0.9(1.0) \\
0.5 \\
0.8 \\
1.0(1.0) \\
0.8(0.9) \\
0.8 \\
1.2 \\
0.9(0.7) \\
1.0 \\
0.4 \\
0.7 \\
1.4\end{array}$ & $\begin{array}{l}0.5(0.6) \\
0.1 \\
0.2 \\
0.7 \\
0.1 \\
0.4 \\
0.5 \\
0.5(0.6) \\
0.5 \\
0.05 \\
0.1 \\
0.6\end{array}$ \\
\hline $\begin{array}{l}\text { Mean } \\
\text { SEM }\end{array}$ & $\mathbf{0}$ & $\begin{array}{l}0.71 \\
0.066\end{array}$ & $\begin{array}{l}0.20 \\
0.046\end{array}$ & $\begin{array}{l}0.15 \\
0.032\end{array}$ & $\begin{array}{l}0.87 \\
0.079\end{array}$ & $\begin{array}{ll}0.35 \\
0.066\end{array}$ \\
\hline
\end{tabular}

* Data within parentheses were obtained by high pressure liquid chromotography analysis; all the others are from microbiological assay. tp $=0.05$ for amoxycillin plus erdosteine $v$ amoxycillin plus placebo. 
PATHOGEN CULTURE AND ANTIBIOTIC

SENSITIVITY

The distribution of patients between the two groups was determined according to the bacteria found in their bronchial secretions (six with Streptococcus pneumoniae, five with Haemophilus influenzae, and one with Staphylococcus aureus) (table 2). Streptococci generally showed greater sensitivity than haemophilus in response to amoxycillin both in vitro and in vivo.

When amoxycillin was given with erdosteine the clearance of pathogens from sputum was faster than when amoxycillin was given alone. Only four patients in the first group (amoxycillin plus erdosteine) had bacteria isolated from their sputum on the fourth day, compared with eight in the second group (amoxycillin alone). Patients in group 1 required six and group 2 eight days' treatment before all the biological specimens became sterile.

In vitro erdosteine showed no antibacterial activity, when tested alone on several bacterial species (namely, Sarcina lutea, Str pneumoniae, Staph aureus, and $H$ influenzae) at concentrations ranging from 0.05 to $50 \mu \mathrm{g} / \mathrm{ml}$, nor did it potentiate the effects of amoxycillin. Moreover, erdosteine did not influence the antibacterial activity of amoxycillin when added to sputum from patients treated with amoxycillin plus placebo.

\section{SERUM AND SPUTUM CONCENTRATIONS}

Mean serum amoxycillin concentrations did not differ between the two groups (fig 1). Amoxycillin was detected in the sputum of all patients regardless of the treatment. The concentration of amoxycillin generally increased with repeated dosing, and the number of patients with concentrations above $0.1 \mu \mathrm{g} / \mathrm{ml}$ rose in both groups (fig 2). The combination of amoxycillin and erdosteine caused significantly higher serum concentrations of amoxycillin, which also persisted for a longer period. Eight hours after the 19th dose none of the patients in the first group had amoxycillin concentrations below $0.1 \mu \mathrm{g} / \mathrm{ml}$, whereas four of the second group had concentrations below this level (table 3 and fig 2).

The high pressure liquid chromatography analysis, carried out in duplicate on some serum (nòt reported) and sputum (data in parentheses in table 3) samples, gave values similar to those obtained with the microbiological assay. It also showed that the retention time for the main chromatographic peak corresponded to that of pure amoxycillin.

\section{Discussion}

The main finding in this study is that when erdosteine, a mucolytic agent that reduces the viscosity of bronchial secretions, is administered in combination with amoxycillin the amoxycillin concentration in the sputum but not the serum of patients with chronic bronchitis during acute infective exacerbations is increased. This effect was accompanied by a faster clinical response to treatment. The present study therefore confirms reports ${ }^{1-5}$ describing the enhancement by other mucolytic agents of antibiotic concentrations in sputum and of their therapeutic effects.

The high pressure liquid chromatography analyses, performed on some biological samples in duplicate, gave values that correlated closely with those of the microbiological assays. Further studies carried out in vitro showed that erdosteine possesses no antibacterial activity, nor does it influence the amoxycillin specific activity, either when tested alone or when added to sputum from amoxycillin plus placebo treated patients. These results exclude the possibility that the clinical effects observed in the presence of erdosteine were due to the antibacterial activity of the drug itself, as described for the mucolytic agent mesna, ${ }^{9}$ or to inhibition of a hypothetical amoxycillin inactivating factor which might interfere with antibiotic bioassay, as reported for tobramycin in sputum from patients with cystic fibrosis. ${ }^{10}$

The mechanism underlying the erdosteine effect is probably related to a specific property: reduction of the viscosity of bronchial secretions. Normal bronchial secretions consist of a plasma exudate with specific mucoproteins and mucopolysaccharides. In chronic bronchitis a higher quantity of viscous fluid is produced; it contains glycoprotein components in a different proportion from that normally observed, and is contaminated with bacteria, breakdown products of bacteria, and leucocytes, including nucleoproteins.

Erdosteine breaks the disulphide bonds that hold the glycoprotein fibres of the mucus together and it accelerates mucociliary transport. ${ }^{611} 12$ As a consequence, amoxycillin can penetrate much better into mucus from either the bloodstream or the bronchial mucosa, and bronchial fluid is eliminated more rapidly. Thus higher local antibiotic concentrations are achieved and bacteria are more effectively suppressed. The results of the present study indicate that erdosteine does not influence the absorption, metabolism, or excretion of amoxycillin and that the therapeutic effectiveness of the specific treatment is related directly to antibiotic concentrations in sputum rather than in serum.

The increased antibiotic concentrations in sputum observed when erdosteine is added to the treatment may be of relevance not only for increasing the rate of suppression of bacterial growth but also in widening the range of antibiotic activity against less sensitive microorganisms. 


\section{References}

1 Buergi H, Regli J, Medici T. Observation on the problems accompanying antibiotic treatment in bronchitis with recurrent infection. Arzneim Forsch 1969;19:776-7.

2 Bach PH, Leary WPP. The effects of bromhexine on oxytetracycline penetrance in sputum. $S$ Afr Med J 1972;46:1512-4.

3 Bergogne-Berezin E, Pierre J, Dournovo P. Etude de l'influence d'un agent mucolytique (bromhexine) sur le passage de l'érythromycine dans les sécrétions bronchiques. Therapie 1979;34:705-11.

$4 \mathrm{Hada} M$. The study about the antibiotic concentration in sputum during treatment with antibiotic or both antibiotic and bisolvon. Medical Treatment 1975; 8:2079-84.

5 Lawson D, Saggers BA. NAC and antibiotics in cystic fibrosis. Br Med J 1965;i:317.

6 Gobetti M, Pedrazzoli A, Bradamante S. DL-S-(2-[N-3- (2-oxo-tetrahydrothienyl)acetamidol])-thioglycolic acid: a novel mucolytic agent of the class of homocys teine thiolactone derivatives. Farmaco 1986;41:69-79을

7 Carlqvist J, Westerlund D. Determination of amoxycillif in body fluids by reversed-phase liquid chromato $\mathbb{Q}$ graphy coupled with a post-column derivatization procedure. J Chromatogr 1979;164:373-81.

8 Campbell MJ. Tetracycline levels in bronchial secretions $\vec{?}$ $J$ Clin Pathol 1970;23:427-34.

9 Heaf DP, Webb GJ, Matthew DJ. In vitro assessment of combined antibiotic and mucolytic treatment fo Pseudomonas aeruginosa infection in cystic fibrosisx Arch Dis Child 1983;58:824-36.

10 Mendelman PM, Smith AL, Levy J, Weber A, Ramsey $B_{00}$ Davis RL. Aminoglycoside penetration, inactivationir and efficacy in cystic fibrosis sputum. Am Rev Respior Dis 1985;132:761-5.

11 Morale MC, Fiumara A, Rizza V. Effect of erdosteine on mucus from human lungs. Med Prax (in press).

12 Gonella J. French patent No 81/0596, 1981. 